\title{
The iron-regulated staphylococcal lipoproteins
}

\section{Jessica R. Sheldon and David E. Heinrichs*}

Department of Microbiology and Immunology, Western University, London, ON, Canada

\section{Edited by:}

Martin J. McGavin, University of Western Ontario, Canada

\section{Reviewed by:}

Fabio Bagnoli, Novartis Vaccines, Italy

John Helmann, Cornell University, USA

\section{${ }^{*}$ Correspondence:}

David E. Heinrichs, Department of Microbiology and Immunology,

Western University, Dental Sciences Building, Room 3014, London, N6A

$5 \mathrm{C} 1 \mathrm{ON}$, Canada.

e-mail:deh@uwo.ca
Lipoproteins fulfill diverse roles in antibiotic resistance, adhesion, protein secretion, signaling and sensing, and many also serve as the substrate binding protein (SBP) partner to $A B C$ transporters for the acquisition of a diverse array of nutrients including peptides, sugars, and scarcely abundant metals. In the staphylococci, the iron-regulated SBPs are significantly upregulated during iron starvation and function to sequester and deliver iron into the bacterial cell, enabling staphylococci to circumvent iron restriction imposed by the host environment. Accordingly, this subset of lipoproteins has been implicated in staphylococcal pathogenesis and virulence. Lipoproteins also activate the host innate immune response, triggered through Toll-like receptor-2 (TLR2) and, notably, the iron-regulated subset of lipoproteins are particularly immunogenic. In this review, we discuss the iron-regulated staphylococcal lipoproteins with regard to their biogenesis, substrate specificity, and impact on the host innate immune response.

Keywords: Staphylococcus, lipoproteins, iron-regulated, iron acquisition, substrate binding protein, TLR2, Fur

\section{INTRODUCTION}

The staphylococci are a diverse group of Gram-positive, catalase-positive facultative anaerobes, consisting of approximately 36 species hosted largely by the human body (Kloos and Bannerman, 1994). Historically, the staphylococci have been broadly divided into two groups based on their coagulase activity with Staphylococcus aureus representing the most notable, coagulase-positive pathogen of the genus. S. aureus is often regarded as the leading cause of infections of the bloodstream, skin, soft tissue, and lower respiratory system (Moet et al., 2007). In contrast, coagulase-negative staphylococci (CoNS) were largely considered to be harmless commensals of the skin and mucous membranes until recent years, when the opportunistically pathogenic $S$. epidermidis has emerged as the most frequent cause of device-associated nosocomial infections (reviewed in Otto, 2012). The appearance of vancomycin-resistance in clinical isolates of both S. aureus and CoNS, in addition to the increasing prevalence of community-associated methicillin-resistant $S$. aureus (CA-MRSA), highlights the continued need to develop novel strategies to combat these global pathogens (Srinivasan et al., 2002; Vandenesch et al., 2003).

The success of the staphylococci has been attributed, in part, to their ability to acquire iron from the host. In contrast to its relative abundance in nature, iron represents a severely growthlimiting nutrient in vivo. Indeed, while the solubility for ferric iron is often cited as $10^{-18} \mathrm{M}$, an adjusted calculation suggests that the actual concentration is closer to $10^{-9}-10^{-10} \mathrm{M}$ at neutral $\mathrm{pH}$ in aerobic environments, based on $\mathrm{Fe}(\mathrm{OH})_{2}^{+}$being the primary species instead of $\mathrm{Fe}(\mathrm{OH})_{3}$ (Ratledge and Dover, 2000). The revised value is still orders of magnitude lower than required to support microbial growth and additionally, iron within the host is further sequestered in glycoproteins such as transferrin and lactoferrin, bound within storage proteins such as ferritin and hemosiderin, or complexed with heme in the form of hemoglobin and myoglobin (Ratledge, 2007). Sequestration of iron functions both in preventing the catalysis of reactions generating damaging free radicals and in providing nutritional immunity against bacterial infection (Schaible and Kaufmann, 2004).

To circumvent the aforementioned restrictions, the staphylococci have evolved a plethora of mechanisms to acquire iron from the host, including the elaboration of multiple siderophores, utilization of xenosiderophores, acquisition of iron from heme and hemoproteins, and the uptake of inorganic free iron (Beasley and Heinrichs, 2010; Haley and Skaar, 2012; Hammer and Skaar, 2011). Each of these systems employs an iron-regulated membrane protein, almost always of the ATP-binding cassette (ABC) transporter superfamily, for import of iron or complexediron across the membrane. In addition to the required ABCtype membrane permease and ATPase (Davidson et al., 2008), these iron-regulated $A B C$ transporters employ a high-affinity membrane-anchored lipoprotein, i.e., a protein bearing an N-terminal, covalently linked lipid (Hutchings et al., 2009), for the specific recognition and binding of the iron substrate; these lipoproteins are analogous to the periplasmic substrate binding proteins (SBPs) of Gram-negative bacteria. Acylation of the hydrophilic protein promotes localization of the lipid into the phospholipid bilayer, anchoring the protein in close proximity to the membrane where it is positioned, once bound by substrate, to interact with its cognate $\mathrm{ABC}$ transporter to facilitate translocation of substrate into the cell. Whereas many other functions have been attributed to lipoproteins in bacteria, including sensing and signaling, protein secretion, antibiotic resistance, adhesion and the uptake of many nutrients in addition to iron (Sutcliffe and Russell, 1995), herein we focus attention solely on the ironregulated lipoproteins (IRLPs) expressed by the staphylococci, given their important roles in staphylococcal pathogenesis and immune stimulation. Of the approximately 50 total lipoproteins encoded by S. aureus, the species in which most of the work has been performed, studies from several laboratories have identified, to date, a total of 9 IRLPs-SirA, HtsA, SstD, FhuD1, FhuD2, 
IsdE, FepA, SitC, and Opp1A. These proteins will be the subject of this review.

\section{CONTROL OF IRON-REGULATED GENE EXPRESSION}

Fur

The ferric uptake regulator (Fur) is a homodimeric metalloprotein that functions as a transcriptional regulator of iron homeostasis in many bacteria. When complexed with iron, Fur regulates the transcription of genes by binding a 19-bp inverted repeat sequence ( $5^{\prime}$-GATAATGATAATCATTATC-3'), known as the Fur box, within the operator/promoter region (Escolar et al., 1999; Baichoo and Helmann, 2002). The Fur protein mainly functions as a repressor, mediating global suppression of iron-responsive genes in response to iron-replete conditions (Xiong et al., 2000; Hantke, 2001; Baichoo et al., 2002). Among the Fur-repressed genes are those involved in iron acquisition; Fur-boxes controlling expression of staphylococcal IRLPs are shown in Figure 1A. Binding of Fur to the Fur box sequences is dependent upon concomitant $\mathrm{Fe}^{2+}$ binding to Fur and, together, the competent DNA-binding complex blocks association of RNA polymerase with promoters, thereby inhibiting transcription. Under iron restriction, intracellular $\mathrm{Fe}^{2+}$ depletion results in dissociation of Fur from DNA, allowing transcription to proceed.

\section{SirR/MntR}

The notable exception to Fur regulation of the IRLPs is the staphylococcal iron transporter, SitABC/MntABC. SitABC and SirR were initially discovered in S. epidermidis (Cockayne et al., 1998), and in Bacillus subtilis where the SitABC and SirR homologues were named MntABCD and MntR, respectively, based on work of Helmann and colleagues in confirming their role in manganese uptake and homeostasis (Que and Helmann, 2000; Glasfeld et al., 2003; Lee and Helmann, 2007). The homologous region in $S$. aureus was likewise identified and referred to as MntABC and MntR (Horsburgh et al., 2002). Expression of sit $A B C / m n t A B C$ is controlled by the diphtheria toxin repressor (DtxR)-like homologue, SirR/MntR (Hill et al., 1998; Horsburgh et al., 2002; Ando et al., 2003). Transcription of sitABC is repressed by SirR in the presence of either $\mathrm{Mn}^{2+}$ or $\mathrm{Fe}^{2+}$ in $S$. epidermidis (Hill et al., 1998), although there is some contention over whether both $\mathrm{Mn}^{2+}$ or $\mathrm{Fe}^{2+}$, or just $\mathrm{Mn}^{2+}$ controls expression in S. aureus (Horsburgh et al., 2002; Ando et al., 2003). Like with Fur, transcription is blocked in the presence of these divalent metal ions because the metal ions facilitate the binding of SirR/MntR to a conserved SirR (or MntR) box (Figure 1A), a region of dyad symmetry in the promoter/operator region of sitABC/mntABC (Hill et al., 1998; Ando et al., 2003). Repression of transcription is relieved when the metal ion concentration is depleted.

\section{LIPOPROTEIN BIOGENESIS}

A detailed and comprehensive analysis of lipoprotein biogenesis is outside the scope of this review, but we refer the reader to a recent review, and references therein, for an excellent summary of lipoprotein biogenesis in bacterial pathogens (Kovacs-Simon et al., 2011). Bacterial preprolipoproteins bear both an N-terminal signal peptide, characteristic of secreted

\section{A Putative Fur Boxes sirA: GATAATGATTCTCATTGTC htsA: GACAATGATAATTGTATC sstD: GATAATGATTATCATTAAT fhuD1: GAAAATGAATATCAATTGA fhuD2: ATGATTGATAATCATTTTC isdE: GACAATGATAATCATTATT fеpA: GATAATTATTATCAACTAG opp1A: GAGAAAAATAATCATTACG}

Putative SirR/MntR Box sitc/ mntC: TTAGGTTAGCCTAAACTTT

B

Lipoprotein signal peptide Lipobox

$\begin{array}{lr}\text { SirA: } & \text { MNKVIKMLVVTLAFLLVILAGC } \\ \text { HtSA : } & \text { MRGLKTFSILGLIVALLIVAAC } \\ \text { SstD: } & \text { MKKTVLYLVLAVMFILAAC } \\ \text { FhuD1 : } & \text { MKRLIGILLCNLFILTAC } \\ \text { FhuD2: } & \text { MKKLLLPLIIMLLVLAAC } \\ \text { IsdE : } & \text { MRIIKYLTILVISVVILTSC } \\ \text { FepA: } & \text { MKKLTTLLLASTLI IAAC } \\ \text { SitC: } & \text { MKKLVPLLLALLLIVAAC } \\ \text { Opp1A : } & \text { MRKLTKMSAMLLTSGLILTGC }\end{array}$

FIGURE 1 | $S$. aureus Fur boxes, SirR/MntR box, and IRLP signal peptides. (A) Fur box sequences within the promoter/operator region of operons encoding the indicated $S$. aureus SBP-encoding gene and the SirR/MntR box located upstream of sitC/mntC. (B) Signal peptides for the indicated IRLPS, with the lipobox indicated by the box. Nucleotide and protein sequences are all derived from $S$. aureus COL.

proteins, and, within the $\mathrm{C}$-region of the signal peptide, a conserved sequence $[\mathrm{L} / \mathrm{V} / \mathrm{I}]_{-3}-[\mathrm{A} / \mathrm{S} / \mathrm{T} / \mathrm{V} / \mathrm{I}]_{-2}-[\mathrm{G} / \mathrm{A} / \mathrm{S}]_{-1}-$ $\mathrm{C}_{+1}$ which is referred to as the lipobox motif (see Figure 1B for lipobox motif of $S$. aureus IRLPs) (Kovacs-Simon et al., 2011). In the first biogenesis reaction, the lipoprotein diacylglyceryl transferase (Lgt) covalently links a diacylglycerol moiety to the thiol group on the side chain of the essential +1 cysteine of the lipobox. The subsequent reaction involves the cleavage of the signal peptide from the diacylated prolipoprotein by lipoprotein signal peptidase (Lsp; alternatively called signal peptidase II), an activity that appears contingent upon lipidation by Lgt in Gram-negative bacteria (Tokunaga et al., 1982), but is not a prerequisite in Gram-positive bacteria (Baumgartner et al., 2007). In a third reaction, highly conserved among Gramnegative bacteria and the Actinomycetes, the enzyme lipoprotein $N$-acyl transferase (Lnt) catalyzes the addition of a third fatty acid to the free amino group of the cysteine, resulting in a triacylated protein. With few exceptions, the lgt, lsp, and $l n t$ genes are indispensible in Gram-negative bacteria, yet in contrast, these 
genes are dispensable in Gram-positive bacteria (reviewed in Kovacs-Simon et al., 2011).

Given the apparent lack of $\ln t$ homologues within Firmicute genomes, it was presumed that lipoproteins within this phylum were diacylated, a notion supported by the identification of diacylated lipoproteins among the staphylococci (Tawaratsumida et al., 2009). In contradistinction, SitC (MntC), the predominant lipoprotein of $S$. aureus and SBP for SitABC (MntABC), was found to be triacylated in multiple $S$. aureus strains and in S. epidermidis (Kurokawa et al., 2009; Asanuma et al., 2011). Furthermore, four other major staphylococcal lipoproteins were found to be triacylated (Asanuma et al., 2011), including the same lipoprotein earlier identified to be diacylated by Tawaratsumida et al. (2009). The discrepancies between these studies could be attributed to differences in culture conditions and preparation of the lipoproteins, given that Asanuma et al. noted a minor presence of diacylated SitC (MntC) lipopeptides in cultures grown at elevated temperatures (Asanuma et al., 2011). The notion of global $N$-acylation among the Firmicutes is further bolstered by a recent report of triacylated lipoproteins among the class Mollicute in Acholeplasma laidlawii, despite the lack of a recognizable Lnt homolog in this bacterium (Serebryakova et al., 2011). Consequently, the nature by, and degree to which, staphylococcal lipoproteins are $N$-acylated remains unknown, and it is possible that an as-yet unidentified enzyme, with no similarity to Gram-negative Lnt enzymes, exists within the Firmicutes that is responsible for this elusive activity.

\section{THE STAPHYLOCOCCAL IRLPS: FUNCTIONS IN IRON ACQUISITION}

The thus-far identified nine IRLPs in the staphylococci are involved in, or at least implicated in, the uptake of iron through either siderophore (Figure 2A) or non-siderophore (Figure 2B) based systems. Together, these systems engender staphylococci with versatility in that they are able to recognize and utilize a broad range of iron substrates. Unsurprisingly, the common function of these IRLP is reflected in their largely conserved overall protein structure.

As a result of a recent revisitation of the classification scheme to segregate SBPs based upon structural characteristics (Berntsson et al., 2010), the majority of the staphylococcal IRLPs, with the exception of FepA and Opp1A (discussed below), fall into cluster A, which consists of class III SBPs associated with ABC transporters. These proteins have an approximately 20 residue long $\alpha$-helical backbone that joins two independently folded domains, each of which consists of central $\beta$-strands surrounded by $\alpha$-helices; substrate is bound into the groove formed between the two domains (Figure 3A). Relative to members of other SBP clusters, hinge motion, upon binding of the substrate, between the two domains of cluster A proteins is restricted by the helical spine. Docking of the cluster A SBPs with their cognate membrane ABC-type permeases is facilitated by salt-bridges formed between conserved glutamic acid residues on the lobes of the SBP (Figure 3A) and patches of positive charge on the exterior surface of the permease, formed by three conserved arginine/lysine residues (Borths et al., 2002).

\section{HtsA AND SirA—RECEPTORS FOR THE FERRATED STAPHYLOFERRIN SIDEROPHORES}

Siderophores are secreted, low-molecular-weight molecules that have high-affinity for ferric iron. Among members of the staphylococci, two siderophores may be produced, staphyloferrin A (SA) and staphyloferrin B (SB) (Konetschny-Rapp et al., 1990; Meiwes et al., 1990; Drechsel et al., 1993; Haag et al., 1994). Enzymes for the synthesis of $\mathrm{SA}$ and $\mathrm{SB}$ are encoded from the $s f a A B C D$ and sbnABCDEFGHI loci, respectively (Dale et al., 2004a,b; Beasley et al., 2009; Cheung et al., 2009; Cotton et al., 2009) (Figure 2A). Adjacent to each of these biosynthetic loci, but transcribed separately, are operons encoding the requisite $\mathrm{ABC}$-transporters for uptake of Fe-SA and Fe-SB complexes (Dale et al., 2004a,b; Beasley et al., 2009, 2011; Beasley and Heinrichs, 2010). The transport systems for the two siderophores have been shown to be non-interchangeable, where HtsABC specifically uptakes Fe-SA and SirABC specifically uptakes Fe-SB (Beasley et al., 2009). While each of the transporter-encoding operons codes for a SBP (HtsA and $\mathrm{SirA}$ ) and a heterodimeric permease component (HtsBC and SirBC), both lack a gene encoding the ATPase component of the $\mathrm{ABC}$ transporter. Instead, at least in S. aureus, FhuC, expressed from the fhuCBG operon (Figure 2A) serves as the ATPase for import of both Fe-SA and Fe-SB (Speziali et al., 2006; Beasley et al., 2009). The notion of a common ATPase between multiple iron acquisition pathways is not unprecedented; the YusV ATPase in B. subtilis acts in the uptake of siderophores through both feuABC and $y f$ fYZyfhA (Ollinger et al., 2006). Currently available genomic sequences reveal that while the hts-sfa locus is found in all staphylococcal genomes (incl. S. aureus, S. epidermidis, S. lugdunensis, S. saprophyticus, S. haemolyticus, S. pseudintermedius, S. warneri, S. capitis, S. caprae, S. hominis, S. carnosus and S. $x y l o s u s$ ), the sir-sbn locus is only found in the genomes of $S$. aureus and S. pseudintermedius. Curiously, however, SB was identified in the supernatants of several members of CoNS, and was first identified in coagulase-variable $S$. hyicus (Konetschny-Rapp et al., 1990; Meiwes et al., 1990; Drechsel et al., 1993); the reason for the discrepancy between these findings and the available genome information remains unknown. Genomes of $S$. lugdunen$s i s$, although possessing $h t s A B C$, carry a deletion of $s f a A$ and $s f a D$, suggesting that this species may utilize Fe-SA as an iron source, but likely does not synthesize either staphyloferrin molecule.

Given that both SA and SB are highly hydrophilic, $\alpha$ hydroxycarboxylate type siderophores (Beasley and Heinrichs, 2010), highly specific binding to their cognate receptors would be necessary to maintain the aforementioned uptake specificity. Without the specific recognition and binding of Fe-SA and FeSB to HtsA and SirA, respectively, one might anticipate that transporters for these structurally similar siderophores would be interchangeable. Recent structural characterizations of both HtsA and SirA have shed significant light on the reason for this specificity. HtsA and SirA both adopt the bilobed, $\alpha$-helical backboned structure typical of the cluster A SBPs (see above), and their binding pockets are shallow and basic to accommodate the negatively charged siderophores, yet few residues within the substrate binding pocket are conserved between the two lipoproteins (Grigg et al., 2010a,b). HtsA coordinates Fe-SA through $\mathrm{H}$-bonding between six arginine residues, directed into 

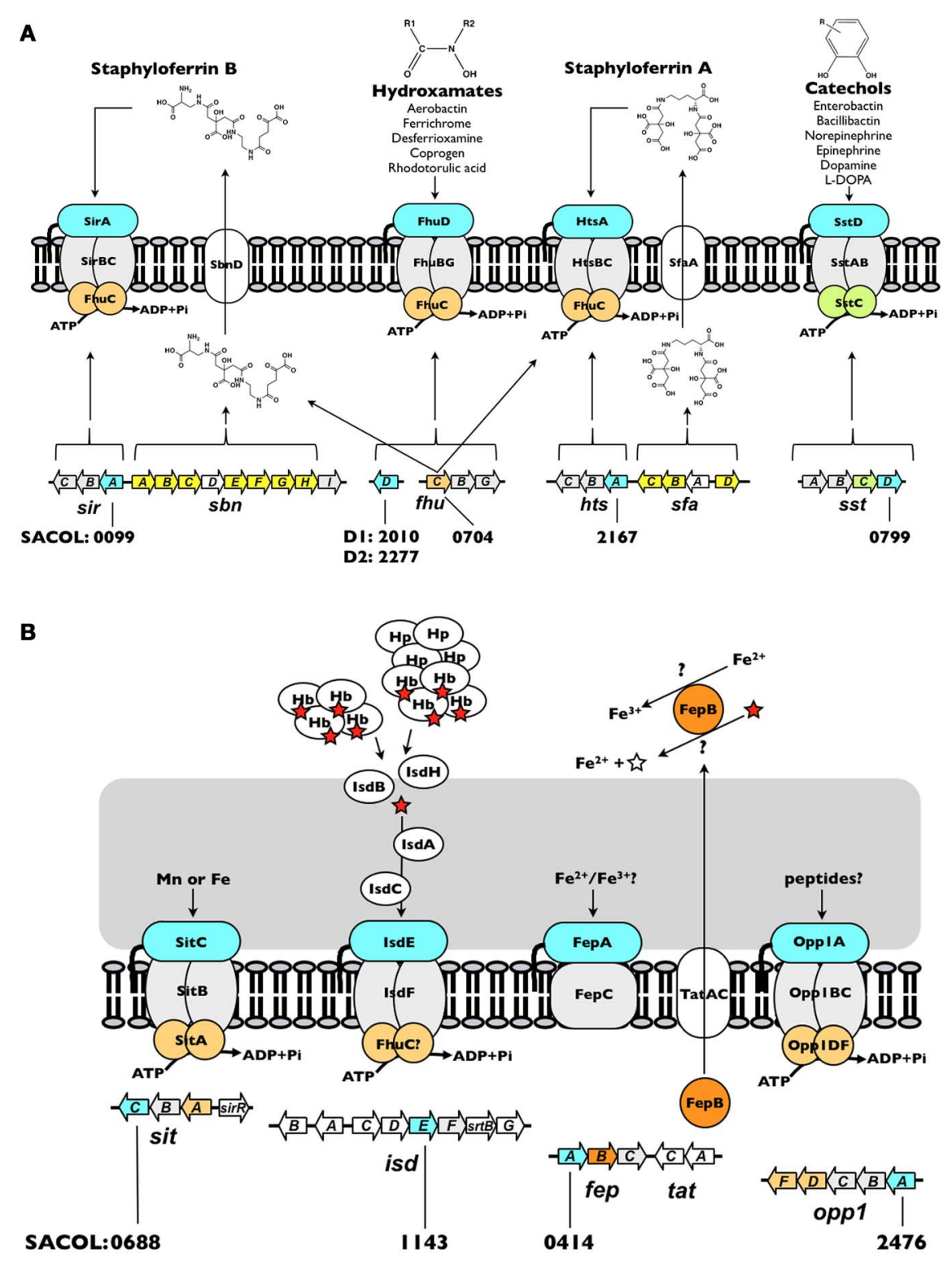

FIGURE 2 | Iron acquisition systems in S. aureus.

(A) Siderophore-dependent iron uptake systems.

(B) Siderophore-independent iron uptake systems. Each system is discussed in the text. The open reading frame accession number, based on $S$. aureus
COL genome, for each of the IRLPS (blue) is indicated. The directionality indicated for each of the genes is as in the genome. The red star represents heme and the open star represents protoporphyrin IX. Hb, hemoglobin; Hp, haptoglobin. the binding pocket, and oxygen atoms in SA (Figure 3B) (Grigg et al., 2010b). Conserved residue R125 also anchors Fe-SB in SirA (Grigg et al., 2010a), however the remaining coordinating residues are unique (Figure $3 \mathbf{C}$ ). The number of coordinating arginine residues is a reflection of the net negative charge on the associated siderophore, where up to six are required to neutralize the -5 net charge on SA, and three are required for the -3 net charge of SB. Furthermore, while siderophore binding to HtsA and SirA induces negligible hinge movement along the $\alpha$-helix, significant and specific conformational changes occur within the C-terminal domain of both (Grigg et al., 2010a,b). The unique coordinating residues, in addition to the distinct conformational changes, likely maintain the specificity and affinity of these receptors for their cognate siderophores, and it is unsurprising that their ligand affinities fall within the nanomolar range (Grigg et al., 2010a,b)

Inactivation of any of the individual biosynthetic or transport loci for SA or SB yields an unimpressive, if any, phenotype when examining for defects in iron-restricted growth (Beasley et al., 2009, 2011). However, the combined inactivation of either $s b n$ together with $s f a$ or sir together with $h t s$ yields mutants with severe growth defects in serum (Beasley et al., 2009, 2011). Notably, the inactivation of multiple transport systems in $S$. aureus results in decreased bacterial fitness during infection, 

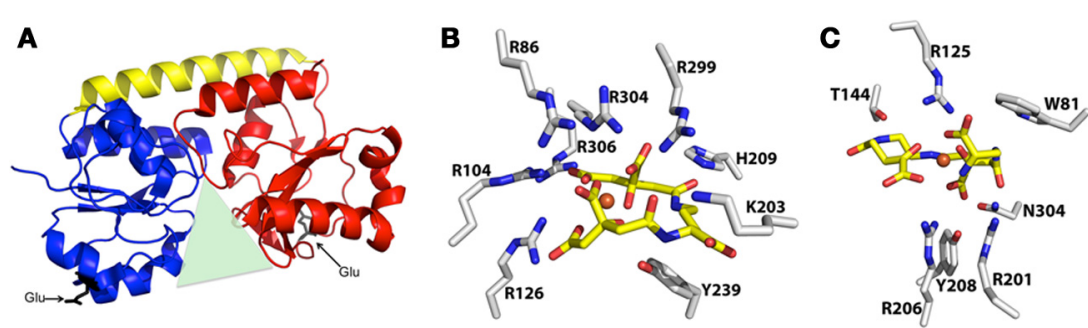

FIGURE 3 | Representative structure of cluster A SBPs, and structures of protein-bound Fe-SA and Fe-SB. (A) Representative ribbon diagram to highlight some of the key characteristics of the cluster A SBPs, including the helical spine (yellow) connecting the alpha/beta N-terminal (blue) and C-terminal (red) lobes that surround the binding pocket (green triangle), and the two conserved glutamic acid residues (black) that interact with the membrane permease. (B) Structure of iron-bound staphyloferrin A with coordinating residues from the $S$. aureus HtsA SBP (PDB 3LI2). (C) Structure of iron-bound staphyloferrin $B$ with coordinating residues from the $S$. aureus SirA SBP (PDB 3MWF). relative to inactivation of the corresponding biosynthetic loci (Beasley et al., 2011), likely due to the continued production of siderophores even in the absence of their cognate receptors, which would enhance iron-starvation in vivo (Beasley et al., 2011). Impairment of receptor function, therefore, represents a potential avenue for therapeutic intervention (see below).

\section{SstD-RECEPTOR FOR FERRATED CATECHOLS/CATECHOLAMINES}

Catechol siderophores, typified by the well-studied enterobactin (or enterochelin), bacillibactin, vibriobactin and salmochelin, are representative of a major class of bacterial siderophores (for a review, see Miethke and Marahiel, 2007). Additionally, the ability of catecholamine stress hormones to stimulate growth of bacteria, including members of CoNS, in the presence of serum (i.e., transferrin) has been studied over the past decade (Freestone et al., 2000, 2008; Neal et al., 2001). Indeed, recent work illuminated how hormones such as epinephrine and norepinephrine are capable of reducing transferrin-bound ferric iron to ferrous iron and thereby liberating iron from this central component of innate immunity (Sandrini et al., 2010). While catechol siderophores have not been identified in culture supernatants of staphylococci, staphylococci are capable of using both catechols and catecholamines as an iron source via the SstABCD ABC transporter (Beasley et al., 2011). The locus (Figure 2A), initially identified through screens for iron-regulated staphylococcal antigens (Morrissey et al., 2000), is highly conserved among S. aureus strains and present in the majority of CoNS. The function of this transporter remained uncharacterized until recently, when sst mutations were characterized in staphyloferrin-deficient strains (Beasley et al., 2011). The sst locus is required for growth promotion by catechol siderophores and catecholamine-liberated transferrin iron, and contributes to in vivo colonization of the murine liver and kidneys. With the exception of the colonization of murine hearts, these in vivo and in vitro effects were otherwise masked in strains synthesizing the staphyloferrins (Beasley et al., 2011).

SstD specifically binds both ferrated catechol siderophores and catecholamine stress hormones with micromolar and submicromolar affinities (Beasley et al., 2011). The reduced affinity of SstD for its ligands, relative to SirA and HtsA, is likely a trade-off in favor of an enhanced range of potential substrates. The closest homologs to SstD include the YclQ protein from B. subtilis and the CeuE protein from Campylobacter jejuni. Structural information exists for these proteins in complex with their ligands; YclQ binds the "stealth" siderophore petrobactin (Zawadzka et al., 2009), while CeuE binds iron complexed by the enterobactin analog, mecam (Muller et al., 2006). Some conservation in the binding mechanism of these proteins is indicated by shared binding pocket residues between SstD, CeuE, and YclQ, which in CeuE interact with the mecam substrate. Crystallographic information for liganded SstD unfortunately remains lacking, but this information would afford insight into the mechanism by which this receptor binds a diverse range of catechol ligands.

\section{FhuD1 AND FhuD2-RECEPTORS FOR FERRIC-HYDROXAMATE SIDEROPHORES}

While the staphylococci have not been demonstrated to synthesize hydroxamate-type siderophores, they are known to be able to utilize them as iron sources. These include aerobactin (produced by some enterobacteriaceae), ferrichrome (produced by the basidiomycete fungus Ustilago sphaerogena), coprogen (produced by Neurospora crassa), and desferrioxamine B, produced by Streptomyces pilosus; the mesylate salt of desferrioxamine B is used clinically under the name Desferal ${ }^{\mathrm{TM}}$ (Brock and Ng, 1983; Sebulsky et al., 2000; Sebulsky and Heinrichs, 2001). Uptake of multiple hydroxamate-type siderophores was similarly demonstrated for B. subtilis (Schneider and Hantke, 1993), and a homologous system identified in the S. aureus (Sebulsky et al., 2000). Ferric-hydroxamate uptake is achieved through the concerted effort of the FhuC ATPase, FhuBG heterodimeric permease, and the independently transcribed substrate-binding lipoproteins, FhuD1 and FhuD2 (Figure 2A) (Sebulsky et al., 2000; Sebulsky and Heinrichs, 2001). All species of staphylococci, with the possible exception of S. hominis and S. xylosus, possess the Fhu uptake system.

While many hydroxamate ligands are common between FhuD1 and FhuD2, the two lipoproteins do possess some unique substrate specificities with FhuD2 exhibiting both a wider range of ligands and greater substrate affinity than FhuD1 (Sebulsky et al., 2003, 2004). While FhuD1 appears to be a less effective 
$\mathrm{Fe}^{3+}$-siderophore SBP than FhuD2, it is certainly possible that the substrates and/or conditions under which FhuD1 are optimal are not defined. While the structures of FhuD1 and FhuD2 are not yet available, structures have been determined for E. coli FhuD bound to several hydroxamate ligands (Clarke et al., 2000, 2002). In contrast to the binding pocket of proteins such as SirA and HtsA, which harbor key charged residues that interact with the siderophore molecule, the structures of $E$. coli FhuD show that the binding of ligands is largely dependent upon hydrophobic contacts; accommodation of several different hydroxamate substrates occurs only through subtle rearrangements of the FhuD protein side-chains.

\section{IsdE-A HEME RECEPTOR}

is $d E$ homologues have been identified in several Gram-positive pathogens including S. aureus, S. lugdunensis, Bacillus anthracis, Clostridium tetani, and Listeria monocytogenes (Skaar and Schneewind, 2004; Heilbronner et al., 2011). The iron-regulated surface determinant pathway (Isd) represents the predominant system for iron acquisition from heme and hemoproteins in S. aureus (Mazmanian et al., 2002, 2003). The proposed architectural arrangement of the nine Isd proteins, facilitated by anchoring to the cell wall through sortase A activity (for IsdA, IsdB, and $\mathrm{IsdH}$ ), and isd locus-encoded sortase B activity (for IsdC), allows for heme, extracted from hemoglobin or haptoglobinhemoglobin, at the cell surface to be shuttled proximal to the membrane where it is bound by the SBP IsdE, and transported into the cytoplasm through the $\mathrm{ABC}$ permease IsdF (Figure 2B) (Mazmanian et al., 2003; Skaar and Schneewind, 2004; Torres et al., 2006; Muryoi et al., 2008; Zhu et al., 2008; Grigg et al., 2010c). Once in the cytoplasm, heme may be degraded by IsdG and IsdI, releasing iron (Skaar et al., 2004a,b; Lee et al., 2008).

As a member of the cluster A SBPs (see above), IsdE possesses the characteristics depicted in Figure $\mathbf{3 A}$ but, unlike SirA and HtsA, bears a deep hydrophobic groove between the two lobes comprising a heme binding pocket (Grigg et al., 2007). A single intermediate or high-spin ferric or, preferentially, low-spin ferrous heme molecule is coordinated by the axial ligands $\mathrm{H} 229$ and M78 (Grigg et al., 2007; Pluym et al., 2007). As with several of the other iron $\mathrm{ABC}$ transporters in the staphylococci, the is $d E F$ genes are not genetically linked with a gene encoding the obligatory ATPase for the transporter. It is possible that the promiscuous FhuC drives transport through IsdEF.

In vitro experiments using purified proteins demonstrated that IsdE could receive heme directly from IsdC (depicted in Figure 2B), as part of a larger study that provided support to the notion that the Isd proteins act together as a heme shuttle system within the bacterial cell wall and membrane (Muryoi et al., 2008). Moreover, growth impairment has been demonstrated for Isd mutants cultured on hemoglobin as a sole iron source (Torres et al., 2006; Pishchany et al., 2009, 2010); subsequent to hemoglobin binding at the cell surface and heme extraction, heme is likely never free from a protein and is shuttled through the wall and membrane via direct Isd-Isd protein contacts. On the contrary, it should be noted, that an isdE mutation had less of an impact when cultured in the presence of heme as a sole iron source (Grigg et al., 2007). The lack of a marked phenotype for the isdE mutant on heme raises the likely possibility that when presented with free heme, a growth-supporting amount of heme makes its way through the cell wall, bypassing the Isd proteins, and is taken into the cell via non-specific mechanisms or by secondary heme transporters, a notion currently under investigation.

\section{FepA-AN IRON RECEPTOR}

The translocation of staphylococcal preprolipoproteins was initially thought to occur exclusively through the dominant secretory pathway, Sec (Driessen and Nouwen, 2008; Natale et al., 2008). However, the twin-arginine translocation pathway (Tat) is another means of lipoprotein translocation across the membrane in a number of Gram-positive, high GC bacteria (McDonough et al., 2005; Widdick et al., 2006, 2011; Thompson et al., 2010), and was recently identified in some (incl. S. aureus, S. haemolyticus and S. carnosus), but not all, staphylococcal genomes. Prefolded proteins bearing a twin arginine motif in their signal peptide are secreted by Tat (Meissner et al., 2007; Biswas et al., 2009), however the role of Tat in the staphylococci appears limited both in the apparent lack of complete Tat homologues in many CoNS, such as S. epidermidis and S. saprophyticus, and in identified substrates (Yamada et al., 2007; Biswas et al., 2009). Currently, the sole identified substrate of Tat is the iron-dependent DyP-family peroxidase, FepB (Biswas et al., 2009).

Dye-decolorizing (DyP)-type peroxidases form a unique heme peroxidase family (for a review, see Sugano, 2009), and members of the family have been reported to have several different substrates (Letoffe et al., 2009; Ahmad et al., 2011; Liers et al., 2011). Insofar as iron uptake is concerned, two Dyp paralogs in E. coli, namely YfeX and EfeB (cytoplasmic and periplasmic enzymes, respectively), were reported to have deferrochelatase activity on heme (Letoffe et al., 2009). Deferrochelation would provide bacteria with an iron source in the absence of dedicated heme uptake systems, however this is currently a subject of some debate. A recent study has argued that the E. coli YfeX protein is not a heme deferrochelatase but rather is a peroxidase that oxidizes porphyrinogens to porphyrins (Dailey et al., 2011). Should DyP-type peroxidases bear deferrochelatase activity, it is possible that, like YfeX and EfeB, staphylococcal FepB could also serve to release ferrous iron from heme.

In addition to $\mathrm{FepB}$, the fep $A B C$ operon, located adjacent to tat $A C$, encodes an iron permease (FepC) and a putative ironbinding lipoprotein (FepA) (Figure 2B). The exact function of S. aureus fepABC in iron acquisition is still under investigation, and the substrate specificity of FepA has not yet been determined. Free ferrous iron released through the potential deferrocheletase activity of FepB could serve as a substrate for FepAC, similar to E. coli ferrous iron-specific efe $U O B$, which has been shown to be induced by growth in aerobic, low $\mathrm{pH}$ and low iron conditions (Grosse et al., 2006; Cao et al., 2007). Alternatively, fepABC may function in elemental iron uptake in a manner analogous to the Ftr1p/Fet3p ferric iron permease in Saccharomyces cerevisiae, where $\mathrm{Fe}^{2+}$ is oxidized to $\mathrm{Fe}^{3+}$ by the multicopper oxidase, Fet3p, and is subsequently transported into the cell by Ftrlp (Kwok et al., 2006). A similar mechanism was first proposed in B. subtilis for $y w b L M N$, a fepABC homologue, and, accordingly, the $y w b L M N$ 
operon was shown essential to the normal growth of $B$. subtilis in iron-restricted media (Ollinger et al., 2006; van der Ploeg et al., 2011). Regardless, the presence of fep operon homologs in many different bacteria, including both Gram-positive and Gram-negative species, suggests a conserved and important functionality. Indeed, S. aureus fep-tat mutants are impaired in inorganic iron uptake and virulence in a murine renal abscess model (Biswas et al., 2009).

Although no structure of a staphylococcal FepA protein has yet been solved, homology searches and structural modeling indicate that it is rather unique among the IRLPs. The closest homologs to FepA are members of the imelysin-like superfamily (Xu et al., 2011). The canonical imelysin fold is all-helical, comprising two similar four-helix bundle domains with a predicted functional site at the domain interface (Xu et al., 2011). Specifically, a conserved GxHxxE motif, also present in staphylococcal FepA proteins, is located at the open end of the binding cleft; this motif has been implicated in the coordination of divalent metal cations (Rajasekaran et al., 2010a,b; Xu et al., 2011). With well over 100 members, the imelysin-like proteins are widely distributed in bacteria and are virtually always located next to a gene encoding a DyP-type peroxidase. Although biochemical evidence is still lacking, this reinforces the assumption that the FepABC-like systems are involved in iron uptake, where the peroxidase potentially converts ferrous iron to ferric iron, which is the ligand for the FepA-like binding proteins.

\section{0pp1A}

Despite being annotated as an oligopeptide permease, opp1ABCDF has no defined role in nitrogen metabolism (Hiron et al., 2007). However, Opp1A, the SBP of this complex, was shown to be significantly upregulated during iron-starvation, both by our laboratory (unpublished data) and others (Hempel et al., 2011), consistent with the identification of a putative Fur box upstream of Opp1A (Figure 1A). The role of oligopeptide permeases in metal ion and heme acquisition is not unprecedented; S. aureus Opp2BCDF and the orphan SBP Opp5A were recently renamed NikBCDE and NikA due to their role in nickel acquisition (Hiron et al., 2010), whereas in E. coli a di-peptide permease is involved in the uptake of both nickel and heme (DppA) (Letoffe et al., 2006, 2008; Shepherd et al., 2007). A potential role for Opp1A in iron acquisition is currently under investigation.

The opp $1 A B C D F$ operon encodes a prototypical oligopeptide permease: two homologous permease proteins (OppB and OppC) and two ATP-binding proteins (OppD and $\mathrm{OppF}$ ), in addition to the peptide/SBP (Figure 2B). Like FepA, Opp1A is not a member of the cluster A SBPs, but instead is a member of cluster $C$ which includes oligopeptide, di-peptide and nickel binding proteins (Berntsson et al., 2010). Cluster C members are characterized by a larger size (approx. $50-70 \mathrm{kDa}$ ) than the cluster A proteins (which are typically in the $30-35 \mathrm{kDa}$ range), a large binding cavity, an extra domain that augments the binding cavity - in some cases to accommodate larger peptide ligands, and ligand binding via a "Venus flytrap" mechanism (Berntsson et al., 2009, 2010). The latter point indicates that these proteins capture their substrates through significant inter-domain hinge movement, unlike the relative lack of inter-domain movement afforded by the helical spine of the cluster A SBPs (see above).

According to Hiron et al. (Hiron et al., 2007), S. aureus possesses two additional oligopeptide permeases (opp3 and opp4) and one di/tri-peptide permease $(d t p T)$, in addition to opp1 and $n i k A / n i k B C D E$. While opp3 and $d t p T$ are involved in nitrogen metabolism (Hiron et al., 2007; Borezee-Durant et al., 2009), the roles of $o p p 1$ and $o p p 4$ are unknown and none of the lipoproteins have been investigated to determine if, like E. coli NikA, they are capable of binding multiple substrates. Although the role of opp 1 is unknown, it has been implicated, along with opp2 and $d t p T$, in staphylococcal infectivity and survival through signature tagged-mutagenesis studies (Mei et al., 1997; Coulter et al., 1998). The exact mechanism by which these permeases contribute to virulence, however, is not known.

\section{SitC/MntC-RECEPTORS FOR IRON OR MANGANESE}

SitC, the lipoprotein component of SitABC (Figure 2B), was first described as an immunogenic iron-repressible cytoplasmic membrane protein (IRMP) in S. epidermidis (Cockayne et al., 1998). The 32-kDa S. epidermidis SitC protein was found both to be expressed by $S$. epidermidis and to react strongly with antibodies in pooled human peritoneal dialysate (HPD) (Williams et al., 1988; Smith et al., 1991; Wilcox et al., 1991; Modun et al., 1992). HPD, the byproduct of continuous ambulatory peritoneal dialysis (CAPD) for renal failure, represents a severely iron-restricted environment (Wallaeys et al., 1986; Williams et al., 1988). Expression of SitC by S. epidermidis and S. aureus isolates known to cause peritonitis in CAPD patients highlighted a potential role for SitC in iron acquisition, and consequently in vivo survival of the staphylococci.

Sequence analysis of SitC revealed that it bears homology both to proteins involved in bacterial adhesion as well as to metal binding proteins (Cockayne et al., 1998). Two of the closest structural homologs to SitC are cluster A SBPs: the zinc-binding TroA protein from Treponema pallidum (PDB 1TOA) and the manganesebinding MntC protein from Synechocystis sp. (PDB 1XVL). Given this, and that SitC is lipid tethered to the cell membrane with distribution throughout the cell wall and minimal surface exposure (Smith et al., 1991; Wilcox et al., 1991; Cockayne et al., 1998), it is unlikely to play a role in bacterial adhesion, although involvement in adhesion has not been conclusively disproven. Greater surface exposure would be expected to promote adhesion, which is seen with the adhesins to which SitC was initially likened, but not for SitC itself (Jenkinson, 1992; Sutcliffe et al., 1993; Cockayne et al., 1998). The relatively porous nature of the cell wall, however, would render SitC accessible to metal cations, such as $\mathrm{Fe}^{2+}$, $\mathrm{Mn}^{2+}$ or $\mathrm{Zn}^{2+}$, as well as to antibodies. Additionally, the extracellular release of lipoproteins during iron starvation, such as SitC, would further contribute to immunogenicity (Cockayne et al., 1998). Despite a proposed role in divalent metal uptake, the fact that expression of $s i t C$ is repressed in the presence of excess $\mathrm{Mn}^{2+}$ or $\mathrm{Fe}^{2+}$ (Hill et al., 1998), and that SitC is highly expressed in vivo, the substrate of SitC in S. epidermidis remains unknown.

In contrast to $S$. epidermidis, the sit $A B C$ homologue in $S$. aureus has an identified function in the transport of $\mathrm{Mn}^{2+}$, and was consequently named $m n t A B C$ (Horsburgh et al., 2002) to 
reflect this activity, following the nomenclature previously used in B. subtilis (Que and Helmann, 2000). While the presence of $\mathrm{Mn}^{2+}$ facilitates repression of $m n t A B C$ through the DtxR-family regulator, $\mathrm{MntR}$ (SirR) (see regulation section, above), the role of iron in mntABC expression is still unclear (Horsburgh et al., 2002; Ando et al., 2003). Furthermore, the structure and characterization of the substrate binding properties of MntC (SitC) have yet to be elucidated. Regardless, with MntC (SitC) being identified as a predominant lipoprotein in S. aureus and S. epidermidis, and the observation that lipoprotein-deficient mutants are both inhibited in iron-restricted growth and in Toll-like receptor 2 (TLR2) activation in the host, it is not surprising that MntC (SitC) contributes an important role in staphylococcal pathogenesis and survival (Stoll et al., 2005; Bubeck Wardenburg et al., 2006; Schmaler et al., 2009, 2010; Muller et al., 2010).

\section{ROLES FOR IRLPS IN IMMUNE RECOGNITION}

The recognition of bacterial invaders by the innate immune system occurs through the identification of pathogen-associated molecular patterns (PAMPs) by Toll-like receptors (TLRs). Of the $>10$ human TLRs currently identified, TLR2, together with the adapter molecule MyD88, represents the main responsive element to Gram-positive cell wall components and, consequently, staphylococcal infection (Takeuchi et al., 1999, 2000a,b). Until recently, the predominant staphylococcal PAMP for induction of TLR2 and a potent inducer of cytokine release was considered to be lipoteichoic acid (LTA) (Schwandner et al., 1999; Morath et al., 2001, 2005). However, it has been shown that the LTA fractions in these experiments were likely contaminated by lipoproteins, the implied true stimuli for TLR2-mediated inflammation (Hashimoto et al., 2006a,b, 2007). The generation of staphylococcal lgt mutants (see biogenesis section, above) has revealed that lipid modification of prelipoproteins is essential to maximal activation of and subsequent NF- $\kappa \mathrm{B}$-dependent cytokine release via TLR2-MyD88, both in vitro and in vivo (Stoll et al., 2005; Bubeck Wardenburg et al., 2006; Kurokawa et al., 2009; Schmaler et al., 2009). Conversely, an LTA-depleted mutant was still capable of inducing TLR2 (Kurokawa et al., 2009). Furthermore, highly purified SitC (MntC) co-localized with and induced TLR2 (Kurokawa et al., 2009; Muller et al., 2010), showing direct evidence of IRLP recognition by the host immune system.

In vivo studies have revealed a paradox in the expression of lipoproteins during infection. Of particular note, sublethal challenge of mice with an $l g t$ mutant resulted in increased mortality relative to the wild-type infection, suggesting that lipoproteins are required to initiate the host innate immune response (Bubeck Wardenburg et al., 2006; Schmaler et al., 2009, 2010). Conversely, the expression of lipoproteins increases bacterial burden during persistent tissue infections, shown to be due to their role in enhancing staphylococcal survival through iron acquisition (Schmaler et al., 2009, 2010). While SitC (MntC) represents the predominant iron-regulated staphylococcal lipoprotein, as previously discussed, S. aureus lacking SitC (MntC) can still stimulate TLR2 (Kurokawa et al., 2009). Given that staphylococcal lipoproteins involved in the acquisition of iron are highly upregulated during iron starvation and expressed in vivo and in vitro (Morrissey et al., 2000; Sebulsky and Heinrichs, 2001; Dale et al., 2004a,b; Skaar et al., 2004a,b; Allard et al., 2006; Hempel et al., 2011), they together likely serve as important PAMPs for TLR2 recognition. Together these results suggest that the elaboration of multiple and sometimes redundant IRLPs may ensure staphylococcal survival in an otherwise inflamed host, providing an intriguing option for the development of potential therapeutics.

\section{CLINICAL APPLICATIONS}

Given their cell surface exposure, propensity to be expressed in vivo and corresponding immunogenicity, the IRLPs represent a tangible target for staphylococcal vaccine development. Indeed, both Sanofi-Pasteur/Syntiron and Novartis are including IRLPs in pre-clinical multivalent vaccine preparations. A discussion of $S$. aureus vaccine attempts is beyond the scope of this review, so we refer the reader to several excellent, recent reviews on the subject (Otto, 2010; Daum and Spellberg, 2012; DeDent et al., 2012; Patti, 2011; Proctor, 2011). The focus of published passive and active immunization efforts targeting iron acquisition systems thus far have centered on the Isd cell wall anchored proteins IsdA, IsdB, and Isd $\mathrm{H}$, with promising results in animal models of S. aureus infection (Clarke et al., 2006; Kuklin et al., 2006; Ebert et al., 2010; Kim et al., 2010; Ster et al., 2010; Arlian and Tinker, 2011; Daum and Spellberg, 2012; DeDent et al., 2012; Harro et al., 2012). Of the Isd proteins, Merck and Intercell took their singleantigen IsdB vaccine, V710 (Kuklin et al., 2006), through phase I clinical trials, demonstrating that the vaccine was immunogenic within 2 weeks of administration and had a good safety profile in humans (Harro et al., 2010, 2012). Phase II/III clinical trials were terminated following a statistical review of the data suggesting that V710 was unlikely to demonstrate a significant benefit to patients (Patti, 2011). Many experts in the field are now suggesting that as opposed to a single-antigen vaccine, multivalent strategies, at least in humans, offer the greatest chance for success. In support of this recommendation, IsdA and IsdB, when combined with two additional $S$. aureus surface antigens, offered greater protective immunity, at least in rodent models, than when the animals were immunized with the individual antigens alone (Stranger-Jones et al., 2006).

In addition to the challenges in mounting an antibody response against the staphylococci (Foster, 2005), the functional redundancy (in terms of supplying a vital iron source to the bacteria) and strain variation in iron-regulated proteins suggests multiple systems should be targeted through a combinatorial vaccine. Indeed, the reduced fitness of sir hts sst mutants relative to single or double mutants recommends targeting multiple iron acquisition lipoproteins to inhibit growth (Beasley et al., 2011). Moreover, effective antibody-based approaches may require antibodies that inhibit protein function, in addition to, or in lieu of, being opsonic. Certainly, protective anti-IsdA and anti-IsdB antibodies appear to function by inhibiting heme acquisition (Kim et al., 2010). Thus, puzzling out the substrate specificities, expression patterns, presence/absence in different strains or species, and relevance, alone or in combination, to in vivo growth/infectivity is paramount toward effective use of the IRLPs as therapeutic targets. Aside of vaccine strategies, other avenues do exist for taking advantage of iron acquisition systems for therapeutic intervention. It is possible that knowledge on the substrate specificities, 
along with detailed structural information, will lead to the use of the uptake systems as portals for toxic "trojan horse" compounds that kill or limit growth of the staphylococci.

\section{CONCLUDING REMARKS}

IRLPs play an essential role in the acquisition of iron, and consequently the in vivo survival of the staphylococci. Paradoxically, these lipoproteins are also strongly immunogenic, inducing an inflammatory response through recognition by TLR2-MyD88. A balance, therefore, exists between the surface display of multiple IRLPs and evading immune recognition by the host. Both of these characteristics make IRLPs a good choice of targets for vaccine development, and the formulation of a combinatorial vaccine targeting multiple iron uptake systems has been suggested to maximize efficacy. Further research is required to

\section{REFERENCES}

Ahmad, M., Roberts, J. N., Hardiman, E. M., Singh, R., Eltis, L. D., and Bugg, T. D. (2011). Identification of DypB from Rhodococcus jostii RHA1 as a lignin peroxidase. Biochemistry 50, 5096-5107.

Allard, M., Moisan, H., Brouillette, E., Gervais, A. L., Jacques, M., Lacasse, P., Diarra, M. S., and Malouin, F. (2006). Transcriptional modulation of some Staphylococcus aureus iron-regulated genes during growth in vitro and in a tissue cage model in vivo. Microbes Infect. 8, 1679-1690.

Ando, M., Manabe, Y. C., Converse, P. J., Miyazaki, E., Harrison, R., Murphy, J. R., and Bishai, W. R. (2003). Characterization of the role of the divalent metal ion-dependent transcriptional repressor MntR in the virulence of Staphylococcus aureus. Infect. Immun. 71, 2584-2590.

Arlian, B. M., and Tinker, J. K. (2011). Mucosal immunization with a Staphylococcus aureus IsdA-cholera toxin A2/B chimera induces antigen-specific Th2-type responses in mice. Clin. Vaccine Immunol. 18, 1543-1551.

Asanuma, M., Kurokawa, K., Ichikawa, R., Ryu, K. H., Chae, J. H., Dohmae, N., Lee, B. L., and Nakayama, H. (2011). Structural evidence of alpha-aminoacylated lipoproteins of Staphylococcus aureus. FEBS J. 278, 716-728.

Baichoo, N., and Helmann, J. D. (2002). Recognition of DNA by fur: a reinterpretation of the fur box consensus sequence. J. Bacteriol. 184, 5826-5832.

Baichoo, N., Wang, T., Ye, R., and Helmann, J. D. (2002). Global analysis of the Bacillus subtilis Fur regulon and the iron starvation stimulon. Mol. Microbiol. 45, 1613-1629.

Baumgartner, M., Karst, U., Gerstel, B., Loessner, M., Wehland, J., and Jansch, L. (2007). Inactivation of Lgt allows systematic characterization of lipoproteins from Listeria monocytogenes. J. Bacteriol. 189, 313-324.

Beasley, F. C., and Heinrichs, D. E. (2010). Siderophore-mediated iron acquisition in the staphylococci. $J$. Inorg. Biochem. 104, 282-288.

Beasley, F. C., Marolda, C. L., Cheung, J., Buac, S., and Heinrichs, D. E. (2011). Staphylococcus aureus Transporters Hts, Sir, and Sst capture iron liberated from human transferrin by staphyloferrin A, staphyloferrin B, and catecholamine stress hormones, respectively, and contribute to virulence. Infect. Immun. 79, 2345-2355.

Beasley, F. C., Vines, E. D., Grigg, J. C., Zheng, Q., Liu, S., Lajoie, G. A., Murphy, M. E., and Heinrichs, D. E. (2009). Characterization of staphyloferrin A biosynthetic and transport mutants in Staphylococcus aureus. Mol. Microbiol. 72, 947-963.

Berntsson, R. P., Doeven, M. K., Fusetti, F., Duurkens, R. H., Sengupta, D., Marrink, S. J., Thunnissen, A. M., Poolman, B., and Slotboom, D. J. (2009). The structural basis for peptide selection by the transport receptor OppA. EMBO J. 28, 1332-1340.

Berntsson, R. P., Smits, S. H., Schmitt, L., Slotboom, D. J., and Poolman, B. (2010). A structural classification of substrate-binding proteins. FEBS Lett. 584, 2606-2617.

Biswas, L., Biswas, R., Nerz, C., Ohlsen, K., Schlag, M., Schafer, T., Lamkemeyer, T., Ziebandt, A. K., Hantke, K., Rosenstein, R., and identify the source of the activity responsible for the $\mathrm{N}$-acylation of staphylococcal lipoproteins. More work should also focus on obtaining high-resolution structural information on each of the proteins discussed here. As iron represents an essential element to survival, the IRLPs remain at the interface of pathogenesis and potential therapeutic control of the often pathogenic staphylococci.

\section{ACKNOWLEDGMENTS}

Jessica R. Sheldon is the recipient of a Canadian Institutes for Health Research Frederick Banting and Charles Best Doctoral Research Award (CIHR-DRA). Work in the authors' laboratory is supported by operating grants (to David E. Heinrichs) from the Canadian Institutes of Health Research and the Natural Sciences and Engineering Research Council of Canada.
Gotz, F. (2009). Role of the twinarginine translocation pathway in Staphylococcus. J. Bacteriol. 191, 5921-5929.

Borezee-Durant, E., Hiron, A., Piard, J. C., and Juillard, V. (2009). Dual role of the oligopeptide permease Opp3 during growth of Staphylococcus aureus in milk. Appl. Environ. Microbiol. 75, 3355-3357.

Borths, E. L., Locher, K. P., Lee, A. T., and Rees, D. C. (2002). The structure of Escherichia coli BtuF and binding to its cognate ATP binding cassette transporter. Proc. Natl. Acad. Sci. U.S.A. 99, 16642-16647.

Brock, J. H., and Ng, J. (1983). The effect of desferrioxamine on the growth of Staphylococcus aureus, Yersinia enterocolitica, and Streptococcus faecalis in human serum. Uptake of desferrioxaminebound iron. FEMS Microbiol. Lett. 20, 439-442.

Bubeck Wardenburg, J., Williams, W. A., and Missiakas, D. (2006). Host defenses against Staphylococcus aureus infection require recognition of bacterial lipoproteins. Proc. Natl. Acad. Sci. U.S.A. 103, 13831-13836.

Cao, J., Woodhall, M. R., Alvarez, J., Cartron, M. L., and Andrews, S. C. (2007). EfeUOB (YcdNOB) is a tripartite, acid-induced and CpxARregulated, low-pH $\mathrm{Fe} 2+$ transporter that is cryptic in Escherichia coli K-12 but functional in $E$. coli O157:H7. Mol. Microbiol. 65, 857-875.

Cheung, J., Beasley, F. C., Liu, S., Lajoie, G. A., and Heinrichs, D. E. (2009). Molecular characterization of staphyloferrin B biosynthesis in Staphylococcus aureus. Mol. Microbiol. 74, 594-608.

Clarke, S. R., Brummell, K. J., Horsburgh, M. J., McDowell, P. W., Mohamad, S. A., Stapleton, M.
R., Acevedo, J., Read, R. C., Day, N. P., Peacock, S. J., Mond, J. J., KokaiKun, J. F., and Foster, S. J. (2006). Identification of in vivo-expressed antigens of Staphylococcus aureus and their use in vaccinations for protection against nasal carriage. $J$. Infect. Dis. 193, 1098-1108.

Clarke, T. E., Braun, V., Winkelmann, G., Tari, L. W., and Vogel, H. J. (2002). X-ray crystallographic structures of the Escherichia coli periplasmic protein FhuD bound to hydroxamate-type siderophores and the antibiotic albomycin. J. Biol. Chem. 277, 13966-13972.

Clarke, T. E., Ku, S. Y., Dougan, D. R., Vogel, H. J., and Tari, L. W. (2000). The structure of the ferric siderophore binding protein FhuD complexed with gallichrome. Nat. Struct. Biol. 7, 287-291.

Cockayne, A., Hill, P. J., Powell, N. B., Bishop, K., Sims, C., and Williams, P. (1998). Molecular cloning of a 32-kilodalton lipoprotein component of a novel iron-regulated Staphylococcus epidermidis ABC transporter. Infect. Immun. 66, 3767-3774.

Cotton, J. L., Tao, J., and Balibar, C. J. (2009). Identification and characterization of the Staphylococcus aureus gene cluster coding for staphyloferrin A. Biochemistry 48, 1025-1035.

Coulter, S. N., Schwan, W. R., Ng, E. Y., Langhorne, M. H., Ritchie, H. D., Westbrock-Wadman, S., Hufnagle, W. O., Folger, K. R., Bayer, A. S., and Stover, C. K. (1998). Staphylococcus aureus genetic loci impacting growth and survival in multiple infection environments. Mol. Microbiol. 30, 393-404.

Dailey, H. A., Septer, A. N., Daugherty, L., Thames, D., Gerdes, S., Stabb, E. V., Dunn, A. K., Dailey, T. A., 
and Phillips, J. D. (2011). The Escherichia coli protein YfeX functions as a porphyrinogen oxidase, not a heme dechelatase. mBio 2, e00248-e00211.

Dale, S. E., Doherty-Kirby, A., Lajoie, G., and Heinrichs, D. E. (2004a). Role of siderophore biosynthesis in virulence of Staphylococcus aureus: identification and characterization of genes involved in production of a siderophore. Infect. Immun. 72, 29-37.

Dale, S. E., Sebulsky, M. T., and Heinrichs, D. E. (2004b). Involvement of SirABC in iron-siderophore import in Staphylococcus aureus. J. Bacteriol. 186, 8356-8362.

Daum, R. S., and Spellberg, B. (2012). Progress toward a Staphylococcus aureus vaccine. Clin. Infect. Dis. 54, 560-567.

Davidson, A. L., Dassa, E., Orelle, C., and Chen, J. (2008). Structure, function, and evolution of bacterial ATP-binding cassette systems. Microbiol. Mol. Biol. Rev. 72, 317-364.

DeDent, A., Kim, H. K., Missiakas, D., and Schneewind, O. (2012). Exploring Staphylococcus aureus pathways to disease for vaccine development. Semin. Immunopathol. 34, 317-333.

Drechsel, H., Freund, S., Nicholson, G., Haag, H., Jung, O., Zahner, H., and Jung, G. (1993). Purification and chemical characterization of staphyloferrin B, a hydrophilic siderophore from staphylococci. Biometals 6, 185-192.

Driessen, A. J., and Nouwen, N. (2008). Protein translocation across the bacterial cytoplasmic membrane. Annu. Rev. Biochem. 77, 643-667.

Ebert, T., Smith, S., Pancari, G., Clark, D., Hampton, R., Secore, S., Towne, V., Fan, H., Wang, X. M., Wu, X., Ernst, R., Harvey, B. R., Finnefrock, A. C., Wang, F., Tan, C., Durr, E., Cope, L., Anderson, A., An, Z., and McNeely, T. (2010). A fully human monoclonal antibody to Staphylococcus aureus iron regulated surface determinant B (IsdB) with functional activity in vitro and in vivo. Hum. Antibodies 19, 113-128.

Escolar, L., Perez-Martin, J., and De Lorenzo, V. (1999). Opening the iron box: transcriptional metalloregulation by the Fur protein. $J$. Bacteriol. 181, 6223-6229.

Foster, T. J. (2005). Immune evasion by staphylococci. Nat. Rev. Microbiol. 3, 948-958.

Freestone, P. P., Lyte, M., Neal, C. P., Maggs, A. F., Haigh, R. D., and Williams, P. H. (2000). The mammalian neuroendocrine hormone norepinephrine supplies iron for bacterial growth in the presence of transferrin or lactoferrin. J. Bacteriol. 182, 6091-6098.

Freestone, P. P., Sandrini, S. M., Haigh, R. D., and Lyte, M. (2008). Microbial endocrinology: how stress influences susceptibility to infection. Trends Microbiol. 16, 55-64.

Glasfeld, A., Guedon, E., Helmann, J. D., and Brennan, R. G. (2003). Structure of the manganese-bound manganese transport regulator of Bacillus subtilis. Nat. Struct. Biol. 10, 652-657.

Grigg, J. C., Cheung, J., Heinrichs, D. E., and Murphy, M. E. (2010a). Specificity of Staphyloferrin B recognition by the SirA receptor from Staphylococcus aureus. J. Biol. Chem. 285, 34579-34588.

Grigg, J. C., Cooper, J. D., Cheung, J., Heinrichs, D. E., and Murphy, M. E. (2010b). The Staphylococcus aureus siderophore receptor HtsA undergoes localized conformational changes to enclose staphyloferrin A in an arginine-rich binding pocket. J. Biol. Chem. 285, 11162-11171.

Grigg, J. C., Ukpabi, G., Gaudin, C. F., and Murphy, M. E. (2010c). Structural biology of heme binding in the Staphylococcus aureus Isd system. J. Inorg. Biochem. 104, 341-348.

Grigg, J. C., Vermeiren, C. L., Heinrichs, D. E., and Murphy, M. E. (2007). Heme coordination by Staphylococcus aureus IsdE. J. Biol. Chem. 282, 28815-28822.

Grosse, C., Scherer, J., Koch, D., Otto, M., Taudte, N., and Grass, G. (2006). A new ferrous iron-uptake transporter, EfeU $(\mathrm{YcdN})$, from Escherichia coli. Mol. Microbiol. 62, 120-131.

Haag, H., Fiedler, H. P., Meiwes, J., Drechsel, H., Jung, G., and Zahner, H. (1994). Isolation and biological characterization of staphyloferrin $\mathrm{B}$, a compound with siderophore activity from staphylococci. FEMS Microbiol. Lett. 115, 125-130.

Haley, K. P., and Skaar, E. P. (2012). A battle for iron: host sequestration and Staphylococcus aureus acquisition. Microbes. Infect. 14, 217-227.

Hammer, N. D., and Skaar, E. P. (2011). Molecular mechanisms of Staphylococcus aureus iron acquisition. Annu. Rev. Microbiol. 65, 129-147.

Hantke, K. (2001). Iron and metal regulation in bacteria. Curr. Opin. Microbiol. 4, 172-177.

Harro, C., Betts, R., Orenstein, W., Kwak, E. J., Greenberg, H. E.,
Onorato, M. T., Hartzel, J., Lipka, J., Dinubile, M. J., and Kartsonis, N. (2010). Safety and immunogenicity of a novel Staphylococcus aureus vaccine: results from the first study of the vaccine dose range in humans. Clin. Vaccine Immunol. 17, 1868-1874.

Harro, C. D., Betts, R. F., Hartzel, J. S., Onorato, M. T., Lipka, J., Smugar, S. S., and Kartsonis, N. A. (2012). The immunogenicity and safety of different formulations of a novel Staphylococcus aureus vaccine (V710): results of two Phase I studies. Vaccine 30, 1729-1736.

Hashimoto, M., Furuyashiki, M., Kaseya, R., Fukada, Y., Akimaru, M., Aoyama, K., Okuno, T., Tamura, T., Kirikae, T., Kirikae, F., Eiraku, N., Morioka, H., Fujimoto, Y., Fukase, K., Takashige, K., Moriya, Y., Kusumoto, S., and Suda, Y (2007). Evidence of immunostimulating lipoprotein existing in the natural lipoteichoic acid fraction. Infect. Immun. 75, 1926-1932.

Hashimoto, M., Tawaratsumida, K., Kariya, H., Aoyama, K., Tamura, T., and Suda, Y. (2006a). Lipoprotein is a predominant Toll-like receptor 2 ligand in Staphylococcus aureus cell wall components. Int. Immunol. 18, 355-362.

Hashimoto, M., Tawaratsumida, K., Kariya, H., Kiyohara, A., Suda, Y., Krikae, F., Kirikae, T., and Gotz, F. (2006b). Not lipoteichoic acid but lipoproteins appear to be the dominant immunobiologically active compounds in Staphylococcus aureus. J. immunol. 177, 3162-3169.

Heilbronner, S., Holden, M. T., Van Tonder, A., Geoghegan, J. A., Foster, T. J., Parkhill, J., and Bentley, S. D. (2011). Genome sequence of Staphylococcus lugdunensis N920143 allows identification of putative colonization and virulence factors. FEMS Microbiol. Lett. 322, 60-67.

Hempel, K., Herbst, F. A., Moche, M., Hecker, M., and Becher, D. (2011). Quantitative proteomic view on secreted, cell surface-associated, and cytoplasmic proteins of the methicillin-resistant human pathogen Staphylococcus aureus under iron-limited conditions. J. Proteome Res. 10, 1657-1666.

Hill, P. J., Cockayne, A., Landers, P., Morrissey, J. A., Sims, C. M., and Williams, P. (1998). SirR, a novel iron-dependent repressor in Staphylococcus epidermidis. Infect. Immun. 66, 4123-4129.

Hiron, A., Borezee-Durant, E., Piard, J. C., and Juillard, V. (2007). Only one of four oligopeptide transport systems mediates nitrogen nutrition in Staphylococcus aureus. J. Bacteriol. 189, 5119-5129.

Hiron, A., Posteraro, B., Carriere, M. Remy, L., Delporte, C., La Sorda, M., Sanguinetti, M., Juillard, V., and Borezee-Durant, E. (2010). A nickel ABC-transporter of Staphylococcus aureus is involved in urinary tract infection. Mol. Microbiol. 77, 1246-1260.

Horsburgh, M. J., Wharton, S. J., Cox, A. G., Ingham, E., Peacock, S., and Foster, S. J. (2002). MntR modulates expression of the PerR regulon and superoxide resistance in Staphylococcus aureus through control of manganese uptake. Mol. Microbiol. 44, 1269-1286.

Hutchings, M. I., Palmer, T. Harrington, D. J., and Sutcliffe, I. C. (2009). Lipoprotein biogenesis in Gram-positive bacteria: knowing when to hold 'em, knowing when to fold 'em. Trends Microbiol. 17, 13-21.

Jenkinson, H. F. (1992). Adherence, coaggregation, and hydrophobicity of Streptococcus gordonii associated with expression of cell surface lipoproteins. Infect. Immun. 60 , 1225-1228.

Kim, H. K., DeDent, A., Cheng, A. G., McAdow, M., Bagnoli, F., Missiakas, D. M., and Schneewind, O. (2010). IsdA and IsdB antibodies protect mice against Staphylococcus aureus abscess formation and lethal challenge. Vaccine 28, 6382-6392.

Kloos, W. E., and Bannerman, T. L. (1994). Update on clinical significance of coagulase-negative staphylococci. Clin. Microbiol. Rev. 7, 117-140.

Konetschny-Rapp, S., Jung, G., Meiwes, J., and Zahner, H. (1990). Staphyloferrin A: a structurally new siderophore from staphylococci. Eur. J. Biochem. 191, 65-74.

Kovacs-Simon, A., Titball, R. W., and Michell, S. L. (2011). Lipoproteins of bacterial pathogens. Infect. Immun. 79, 548-561.

Kuklin, N. A., Clark, D. J., Secore, S., Cook, J., Cope, L. D., McNeely, T., Noble, L., Brown, M. J., Zorman, J. K., Wang, X. M., Pancari, G., Fan, H., Isett, K., Burgess, B., Bryan, J., Brownlow, M., George, H., Meinz, M., Liddell, M. E., Kelly, R., Schultz, L., Montgomery, D., Onishi, J., Losada, M., Martin, M., Ebert, T., Tan, C. Y., Schofield, T. L., Nagy, E., Meineke, A., Joyce, J. G., Kurtz, M. B., Caulfield, M. J., Jansen, K. U., McClements, W., and Anderson, A. S. (2006). A novel Staphylococcus aureus vaccine: iron surface determinant B induces 
rapid antibody responses in rhesus macaques and specific increased survival in a murine $S$. aureus sepsis model. Infect. Immun. 74 , 2215-2223.

Kurokawa, K., Lee, H., Roh, K. B., Asanuma, M., Kim, Y. S., Nakayama, H., Shiratsuchi, A., Choi, Y., Takeuchi, O., Kang, H. J., Dohmae, N., Nakanishi, Y., Akira, S., Sekimizu, K., and Lee, B. L. (2009). The triacylated ATP binding cluster transporter substrate-binding lipoprotein of Staphylococcus aureus functions as a native ligand for toll-like receptor 2 . J. Biol. Chem. 284, 8406-8411.

Kwok, E. Y., Severance, S., and Kosman, D. J. (2006). Evidence for iron channeling in the Fet3p-Ftrlp high-affinity iron uptake complex in the yeast plasma membrane. Biochemistry 45, 6317-6327.

Lee, J. W., and Helmann, J. D. (2007). Functional specialization within the Fur family of metalloregulators. Biometals 20, 485-499.

Lee, W. C., Reniere, M. L., Skaar, E. P., and Murphy, M. E. (2008). Ruffling of metalloporphyrins bound to IsdG and IsdI, two heme-degrading enzymes in Staphylococcus aureus. J. Biol. Chem. 283, 30957-30963.

Letoffe, S., Delepelaire, P., and Wandersman, C. (2006). The housekeeping dipeptide permease is the Escherichia coli heme transporter and functions with two optional peptide binding proteins. Proc. Natl. Acad. Sci. U.S.A. 103, 12891-12896.

Letoffe, S., Delepelaire, P., and Wandersman, C. (2008). Functional differences between heme permeases: Serratia marcescens HemTUV permease exhibits a narrower substrate specificity (restricted to heme) than the Escherichia coli DppABCDF peptide-heme permease. J. Bacteriol. 190, 1866-1870.

Letoffe, S., Heuck, G., Delepelaire, P., Lange, N., and Wandersman, C. (2009). Bacteria capture iron from heme by keeping tetrapyrrol skeleton intact. Proc. Natl. Acad. Sci. U.S.A. 106, 11719-11724.

Liers, C., Ullrich, R., Hofrichter, M., Minibayeva, F. V., and Beckett, R. P. (2011). A heme peroxidase of the ascomyceteous lichen Leptogium saturninum oxidizes high-redox potential substrates. Fungal. Genet. Biol. 48, 1139-1145.

Mazmanian, S. K., Skaar, E. P., Gaspar, A. H., Humayun, M., Gornicki, P., Jelenska, J., Joachmiak, A., Missiakas, D. M., and Schneewind, O. (2003). Passage of heme-iron across the envelope of Staphylococcus aureus. Science 299, 906-909.

Mazmanian, S. K., Ton-That, H., Su, K., and Schneewind, O. (2002). An iron-regulated sortase anchors a class of surface protein during Staphylococcus aureus pathogenesis. Proc. Natl. Acad. Sci. U.S.A. 99, 2293-2298.

McDonough, J. A., Hacker, K. E., Flores, A. R., Pavelka, M. S. Jr., and Braunstein, M. (2005). The twin-arginine translocation pathway of Mycobacterium smegmatis is functional and required for the export of mycobacterial beta-lactamases. J. Bacteriol. 187, 7667-7679.

Mei, J.-M., Nourbakhsh, F., Ford, C. W., and Holden, D. W. (1997). Identification of Staphylococcus aureus virulence genes in a murine model of bacteraemia using signature-tagged mutagenesis. Mol. Microbiol. 26, 399-407.

Meissner, D., Vollstedt, A., Van Dijl, J. M., and Freudl, R. (2007). Comparative analysis of twinarginine (Tat)-dependent protein secretion of a heterologous model protein (GFP) in three different Gram-positive bacteria. Appl. Microbiol. Biotechnol. 76, 633-642.

Meiwes, J., Fiedler, H.-P., Haag, H., Zähner, H., Konetschny-Rapp, S., and Jung, G. (1990). Isolation and characterization of staphyloferrin A, a compound with siderophore activity from Staphylococcus hyicus DSM 20459. FEMS Microbiol. Lett. 67, 201-206.

Modun, B., Williams, P., Pike, W. J., Cockayne, A., Arbuthnott, J. P., Finch, R., and Denyer, S. P. (1992). Cell envelope proteins of Staphylococcus epidermidis grown in vivo in a peritoneal chamber implant. Infect. Immun. 60 , 2551-2553.

Miethke, M., and Marahiel, M. A. (2007). Siderophore-based iron acquisition and pathogen control. Microbiol. Mol. Biol. Rev. 71, 413-451.

Moet, G. J., Jones, R. N., Biedenbach, D. J., Stilwell, M. G., and Fritsche, T. R. (2007). Contemporary causes of skin and soft tissue infections in North America, Latin America, and Europe: report from the SENTRY Antimicrobial Surveillance Program (1998-2004). Diagn. Microbiol. Infect. Dis. 57, 7-13.

Morath, S., Geyer, A., and Hartung, T. (2001). Structure-function relationship of cytokine induction by lipoteichoic acid from
Staphylococcus aureus. J. Exp. Med. 193, 393-397.

Morath, S., Von Aulock, S., and Hartung, T. (2005). Structure/function relationships of lipoteichoic acids. J. Endotoxin. Res. $11,348-356$.

Morrissey, J. A., Cockayne, A., Hill, P. J., and Williams, P. (2000). Molecular cloning and analysis of a putative siderophore $\mathrm{ABC}$ transporter from Staphylococcus aureus. Infect. Immun. 68, 6281-6288.

Muller, A., Wilkinson, A. J., Wilson, K. S., and Duhme-Klair, A. K. (2006). An $\left[\{\mathrm{Fe}(\text { mecam })\}_{2}\right]^{6}$-bridge in the crystal structure of a ferric enterobactin binding protein. Angew. Chem. Int. Ed. Engl. 45, 5132-5136.

Muller, P., Muller-Anstett, M., Wagener J., Gao, Q., Kaesler, S., Schaller, M. Biedermann, T., and Gotz, F. (2010). The Staphylococcus aureus lipoprotein SitC colocalizes with Toll-like receptor 2 (TLR2) in murine keratinocytes and elicits intracellular TLR2 accumulation. Infect. Immun 78, 4243-4250.

Muryoi, N., Tiedemann, M. T., Pluym, M., Cheung, J., Heinrichs, D. E., and Stillman, M. J. (2008) Demonstration of the ironregulated surface determinant (Isd) heme transfer pathway in Staphylococcus aureus. J. Biol. Chem. 283, 28125-28136.

Natale, P., Bruser, T., and Driessen, A. J. (2008). Sec- and Tat-mediated protein secretion across the bacterial cytoplasmic membrane-distinct translocases and mechanisms. Biochim. Biophys. Acta 1778, 1735-1756.

Neal, C. P., Freestone, P. P., Maggs, A. F., Haigh, R. D., Williams, P. H., and Lyte, M. (2001). Catecholamine inotropes as growth factors for Staphylococcus epidermidis and other coagulase-negative staphylococci. FEMS Microbiol. Lett. 194, 163-169.

Ollinger, J., Song, K. B., Antelmann, H., Hecker, M., and Helmann, J. D. (2006). Role of the Fur regulon in iron transport in Bacillus subtilis. J. Bacteriol. 188, 3664-3673.

Otto, M. (2010). Novel targeted immunotherapy approaches for staphylococcal infection. Expert. Opin. Biol. Ther. 10, 1049-1059.

Otto, M. (2012). Molecular basis of Staphylococcus epidermidis infections. Semin. Immunopathol. 34, 201-214.

Patti, J. M. (2011). Will we ever see the approval of a Staphylococcus aureus vaccine? Expert Rev. Anti Infect. Ther. 9, 845-846.
Pishchany, G., Dickey, S. E., and Skaar, E. P. (2009). Subcellular localization of the Staphylococcus aureus heme iron transport components IsdA and IsdB. Infect. Immun. 77, 2624-2634.

Pishchany, G., McCoy, A. L., Torres, V. J., Krause, J. C., Crowe, J. E. Jr., Fabry, M. E., and Skaar, E. P. (2010). Specificity for human hemoglobin enhances Staphylococcus aureus infection. Cell Host Microbe 8, 544-550.

Pluym, M., Vermeiren, C. L., Mack, J., Heinrichs, D. E., and Stillman, M. J. (2007). Heme binding properties of Staphylococcus aureus IsdE. Biochemistry 46, 12777-12787.

Proctor, R. (2011). Is there a future for a Staphylococcus aureus vaccine? Vaccine 21. [Epub ahead of print].

Que, Q., and Helmann, J. D. (2000). Manganese homeostasis in Bacillus subtilis is regulated by MntR, a bifunctional regulator related to the diphtheria toxin repressor family of proteins. Mol. Microbiol. 35, 1454-1468.

Rajasekaran, M. B., Mitchell, S. A., Gibson, T. M., Hussain, R., Siligardi, G., Andrews, S. C., and Watson, K. A. (2010a). Isolation and characterisation of EfeM, a periplasmic component of the putative EfeUOBM iron transporter of Pseudomonas syringae pv. syringae. Biochem. Biophys. Res. Commun. 398, 366-371.

Rajasekaran, M. B., Nilapwar, S., Andrews, S. C., and Watson, K. A. (2010b). EfeO-cupredoxins: major new members of the cupredoxin superfamily with roles in bacterial iron transport. Biometals 23, 1-17.

Ratledge, C. (2007). Iron metabolism and infection. Food Nutr. Bull. 28, S515-S523.

Ratledge, C., and Dover, L. G. (2000) Iron metabolism in pathogenic bacteria. Annu. Rev. Microbiol. 54, 881-941.

Sandrini, S. M., Shergill, R., Woodward, J., Muralikuttan, R., Haigh, R. D., Lyte, M., and Freestone, P. P. (2010). Elucidation of the mechanism by which catecholamine stress hormones liberate iron from the innate immune defense proteins transferrin and lactoferrin. J. Bacteriol. 192, 587-594.

Schaible, U. E., and Kaufmann, S. H. (2004). Iron and microbial infection. Nat. Rev. Microbiol. 2, 946-953.

Schmaler, M., Jann, N. J., Ferracin, F., Landolt, L. Z., Biswas, L., Gotz, F., and Landmann, R. (2009). Lipoproteins in Staphylococcus 
aureus mediate inflammation by TLR2 and iron-dependent growth in vivo. J. Immunol. 182, 7110-7118. Schmaler, M., Jann, N. J., Gotz, F., and Landmann, R. (2010). Staphylococcal lipoproteins and their role in bacterial survival in mice. Int. J. Med. Microbiol. 300, 155-160.

Schneider, R., and Hantke, K. (1993). Iron-hydroxamate uptake systems in Bacillus subtilis: identification of a lipoprotein as part of a binding protein-dependent transport system. Mol. Microbiol. 8, 111-121.

Schwandner, R., Dziarski, R., Wesche, H., Rothe, M., and Kirschning, C. J. (1999). Peptidoglycan- and lipoteichoic acid-induced cell activation is mediated by toll-like receptor $2 . \mathrm{J}$. Biol. Chem. 274, 17406-17409.

Sebulsky, M. T., and Heinrichs, D. E. (2001). Identification and characterization of fhuD1 and fhuD2, two genes involved in iron-hydroxamate uptake in Staphylococcus aureus. J. Bacteriol. 183, 4994-5000.

Sebulsky, M. T., Hohnstein, D., Hunter, M. D., and Heinrichs, D. E. (2000). Identification and characterization of a membrane permease involved in iron-hydroxamate transport in Staphylococcus aureus. J. Bacteriol. 182, 4394-4400.

Sebulsky, M. T., Shilton, B. H., Speziali, C. D., and Heinrichs, D. E. (2003). The role of FhuD2 in iron(III)-hydroxamate transport in Staphylococcus aureus. Demonstration that FhuD2 binds iron(III)-hydroxamates but with minimal conformational change and implication of mutations on transport. J. Biol. Chem. 278, 49890-49900.

Sebulsky, M. T., Speziali, C. D., Shilton, B. H., Edgell, D. R., and Heinrichs, D. E. (2004). FhuD1, a ferric hydroxamate-binding lipoprotein in Staphylococcus aureus: a case of gene duplication and lateral transfer. $J$. Biol. Chem. 279, 53152-53159.

Serebryakova, M. V., Demina, I. A., Galyamina, M. A., Kondratov, I. G., Ladygina, V. G., and Govorun, V. M. (2011). The acylation state of surface lipoproteins of mollicute Acholeplasma laidlawii. J. Biol. Chem. 286, 22769-22776.

Shepherd, M., Heath, M. D., and Poole, R. K. (2007). NikA binds heme: a new role for an Escherichia coli periplasmic nickelbinding protein. Biochemistry 46, 5030-5037.

Skaar, E. P., Gaspar, A. H., and Schneewind, O. (2004a). IsdG and
IsdI, heme-degrading enzymes in the cytoplasm of Staphylococcus aureus. J. Biol. Chem. 279, 436-443.

Skaar, E. P., Humayun, M., Bae, T., Debord, K. L., and Schneewind, O. (2004b). Iron-source preference of Staphylococcus aureus infections. Science 305, 1626-1628.

Skaar, E. P., and Schneewind, O. (2004). Iron-regulated surface determinants (Isd) of Staphylococcus aureus: stealing iron from heme. Microbes. Infect. 6, 390-397.

Smith, D. G., Wilcox, M. H., Williams, P., Finch, R. G., and Denyer, S. P. (1991). Characterization of cell envelope proteins of Staphylococcus epidermidis cultured in human peritoneal dialysate. Infect. Immun. 59, 617-624.

Speziali, C. D., Dale, S. E., Henderson, J. A., Vines, E. D., and Heinrichs, D. E. (2006). Requirement of Staphylococcus aureus ATP-binding cassette-ATPase FhuC for ironrestricted growth and evidence that it functions with more than one iron transporter. J. Bacteriol. 188, 2048-2055.

Srinivasan, A., Dick, J. D., and Perl, T. M. (2002). Vancomycin resistance in staphylococci. Clin. Microbiol. Rev. $15,430-438$.

Ster, C., Beaudoin, F., Diarra, M. S., Jacques, M., Malouin, F., and Lacasse, P. (2010). Evaluation of some Staphylococcus aureus ironregulated proteins as vaccine targets. Vet. Immunol. Immunopathol. 136, 311-318.

Stoll, H., Dengjel, J., Nerz, C., and Gotz, F. (2005). Staphylococcus aureus deficient in lipidation of prelipoproteins is attenuated in growth and immune activation. Infect. Immun. 73, 2411-2423.

Stranger-Jones, Y. K., Bae, T., and Schneewind, O. (2006). Vaccine assembly from surface proteins of Staphylococcus aureus. Proc. Natl. Acad. Sci. U.S.A. 103, 16942-16947.

Sugano, Y. (2009). DyP-type peroxidases comprise a novel heme peroxidase family. Cel. Mol. Life Sci. 66, 1387-1403.

Sutcliffe, I. C., and Russell, R. R. B. (1995). Lipoproteins of Grampositive bacteria. J. Bacteriol. 177, 1123-1128.

Sutcliffe, I. C., Tao, L., Ferretti, J. J., and Russell, R. R. B. (1993). MsmE, a lipoprotein involved in sugar transport in Streptococcus mutans. J. Bacteriol. 175, 1853-1855.

Takeuchi, O., Hoshino, K., and Akira, S. (2000a). Cutting edge:
TLR2-deficient and MyD88deficient mice are highly susceptible to Staphylococcus aureus infection. J. Immunol. 165, 5392-5396.

Takeuchi, O., Hoshino, K., Kawai, T., Sanjo, H., Takada, H., Ogawa, T., Takeda, K., and Akira, S. (1999). Differential roles of TLR2 and TLR4 in recognition of gram-negative and gram-positive bacterial cell wall components. Immunity 11, 443-451.

Takeuchi, O., Takeda, K., Hoshino, K., Adachi, O., Ogawa, T., and Akira S. (2000b). Cellular responses to bacterial cell wall components are mediated through MyD88dependent signaling cascades. Int Immunol. 12, 113-117.

Tawaratsumida, K., Furuyashiki, M., Katsumoto, M., Fujimoto, Y., Fukase, K., Suda, Y., and Hashimoto, M. (2009). Characterization of N-terminal structure of TLR2-activating lipoprotein in Staphylococcus aureus. J. Biol. Chem. 284 9147-9152.

Thompson, B. J., Widdick, D. A., Hicks, M. G., Chandra, G., Sutcliffe, I. C., Palmer, T., and Hutchings, $M$ I. (2010). Investigating lipoprotein biogenesis and function in the model Gram-positive bacterium Streptomyces coelicolor. Mol. Microbiol. 77, 943-957.

Tokunaga, M., Tokunaga, H., and Wu, H. C. (1982). Post-translational modification and processing of Escherichia coli prolipoprotein in vitro. Proc. Natl. Acad. Sci. U.S.A. 79, 2255-2259.

Torres, V. J., Pishchany, G., Humayun, M., Schneewind, O., and Skaar, E. P. (2006). Staphylococcus aureus IsdB is a hemoglobin receptor required for heme iron utilization. J. Bacteriol. 188, 8421-8429.

van der Ploeg, R., Mader, U., Homuth, G., Schaffer, M., Denham, E. L., Monteferrante, C. G., Miethke, M., Marahiel, M. A., Harwood, C. R. Winter, T., Hecker, M., Antelmann, H., and Van Dijl, J. M. (2011). Environmental salinity determines the specificity and need for Tatdependent secretion of the YwbN protein in Bacillus subtilis. PloS One 6:e18140. doi: 10.1371/journal.pone. 0018140

Vandenesch, F., Naimi, T., Enright, M. C., Lina, G., Nimmo, G. R., Heffernan, H., Liassine, N., Bes, M., Greenland, T., Reverdy, M. E., and Etienne, J. (2003). Communityacquired methicillin-resistant Staphylococcus aureus carrying Panton-Valentine leukocidin genes: worldwide emergence. Emerg. Infect. Dis. 9, 978-984.

Wallaeys, B., Cornelis, R., Mees, L., and Lameire, N. (1986). Trace elements in serum, packed cells, and dialysate of CAPD patients. Kidney Int. 30, 599-604.

Widdick, D. A., Dilks, K., Chandra, G., Bottrill, A., Naldrett, M., Pohlschroder, M., and Palmer, T. (2006). The twin-arginine translocation pathway is a major route of protein export in Streptomyces coelicolor. Proc. Natl. Acad. Sci. U.S.A. 103, 17927-17932.

Widdick, D. A., Hicks, M. G., Thompson, B. J., Tschumi, A., Chandra, G., Sutcliffe, I. C., Brulle, J. K., Sander, P., Palmer, T., and Hutchings, M. I. (2011). Dissecting the complete lipoprotein biogenesis pathway in Streptomyces scabies. Mol. Microbiol. 80, 1395-1412.

Wilcox, M. H., Williams, P., Smith, D. G., Modun, B., Finch, R. G., and Denyer, S. P. (1991). Variation in the expression of cell envelope proteins of coagulase-negative staphylococci cultured under ironrestricted conditions in human peritoneal dialysate. J. Gen. Microbiol. 137, 2561-2570.

Williams, P., Denyer, S. P., and Finch, R. G. (1988). Protein antigens of Staphylococcus epidermidis grown under iron-restricted conditions in human peritoneal dialysate. FEMS Microbiol. Lett. 50, 29-33.

Xiong, A., Singh, V. K., Cabrera, G., and Jayaswal, R. K. (2000). Molecular characterization of the ferric-uptake regulator, Fur, from Staphylococcus aureus. Microbiology 146, 659-668.

Xu, Q., Rawlings, N. D., Farr, C. L., Chiu, H. J., Grant, J. C., Jaroszewski, L., Klock, H. E., Knuth, M. W., Miller, M. D., Weekes, D., Elsliger, M. A., Deacon, A. M., Godzik, A., Lesley, S. A., and Wilson, I. A. (2011). Structural and sequence analysis of imelysin-like proteins implicated in bacterial iron uptake. PloS One 6:e21875. doi: 10.1371/journal.pone.0021875

Yamada, K., Sanzen, I., Ohkura, T., Okamoto, A., Torii, K., Hasegawa, T., and Ohta, M. (2007). Analysis of twin-arginine translocation pathway homologue in Staphylococcus aureus. Curr. Microbiol. 55, 14-19.

Zawadzka, A. M., Kim, Y., Maltseva, N., Nichiporuk, R., Fan, Y., Joachimiak, A., and Raymond, K. N. (2009). Characterization of a Bacillus subtilis transporter for petrobactin, 
an anthrax stealth siderophore. Proc. Natl. Acad. Sci. U.S.A. 106, 21854-21859.

Zhu, H., Xie, G., Liu, M., Olson, J. S., Fabian, M., Dooley, D. M., and Lei, B. (2008). Pathway for heme uptake from human methemoglobin by the iron-regulated surface determinants system of Staphylococcus aureus. J. Biol. Chem. 283, Received: 18 January 2012; paper $18450-18460$.

Conflict of Interest Statement: The authors declare that the research was conducted in the absence of any commercial or financial relationships that could be construed as a potential conflict of interest. pending published: 04 February 2012 accepted: 13 March 2012; published online: 04 April 2012.

Citation: Sheldon JR and Heinrichs DE (2012) The iron-regulated staphylococcal lipoproteins. Front. Cell. Inf. Microbio. 2:41. doi: 10.3389/fcimb. 2012.00041
Copyright (C) 2012 Sheldon and Heinrichs. This is an open-access article distributed under the terms of the Creative Commons Attribution Non Commercial License, which permits non-commercial use, distribution, and reproduction in other forums, provided the original authors and source are credited. 